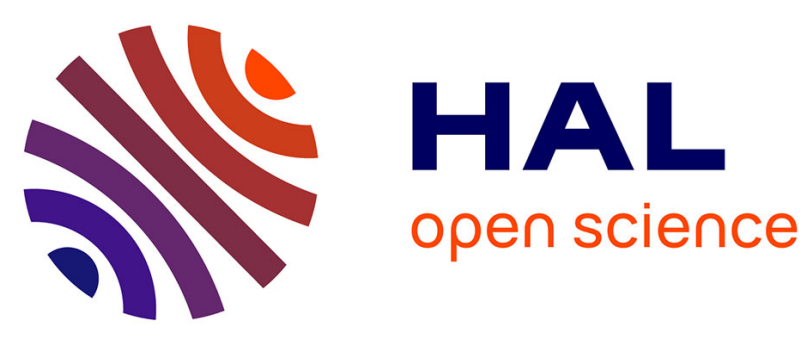

\title{
Polypyridyl Ruthenium Complexes: Versatile Tools for Linear and Non-Linear Optics
}

\author{
Nicolas Durand, Paul Savel, Huriye Akdas-Kiliç, Abdou Boucekkine, \\ Jean-Pierre Malval, Jean-Luc Fillaut
}

\section{- To cite this version:}

Nicolas Durand, Paul Savel, Huriye Akdas-Kiliç, Abdou Boucekkine, Jean-Pierre Malval, et al.. Polypyridyl Ruthenium Complexes: Versatile Tools for Linear and Non-Linear Optics. 21st International Conference on Transparent Optical Networks ICTON 2019, Jul 2019, Angers, France. hal02328886

\section{HAL Id: hal-02328886}

\section{https://hal-univ-rennes1.archives-ouvertes.fr/hal-02328886}

Submitted on 23 Oct 2019

HAL is a multi-disciplinary open access archive for the deposit and dissemination of scientific research documents, whether they are published or not. The documents may come from teaching and research institutions in France or abroad, or from public or private research centers.
L'archive ouverte pluridisciplinaire HAL, est destinée au dépôt et à la diffusion de documents scientifiques de niveau recherche, publiés ou non, émanant des établissements d'enseignement et de recherche français ou étrangers, des laboratoires publics ou privés. 


\title{
Polypyridyl Ruthenium Complexes: Versatile Tools for Linear and Non-Linear Optics
}

\author{
Nicolas Durand, ${ }^{1}$ Paul Savel, ${ }^{1}$ Huriye Akdas-Kiliç, ${ }^{1}$ Abdou Boucekkine, ${ }^{1}$ Jean-Pierre Malval, ${ }^{2}$ Jean-Luc \\ Fillaut $^{1 *}$ \\ ${ }^{1}$ Univ Rennes, CNRS, ISCR (Institut des Sciences Chimiques de Rennes) - \\ UMR 6226, F-35000 Rennes, France \\ *e-mail: jean-luc.fillaut@univ-rennes1.fr \\ ${ }^{2}$ Institut de Science des Matériaux de Mulhouse \\ UMR 7361 CNRS - Université de Haute-Alsace, BP 2488 \\ 68057 Mulhouse cedex, France
}

\begin{abstract}
Coordination complexes have been attracting considerable interest due to their potential nonlinear optical (NLO) properties and applications in optoelectronic and photonic devices. Incorporation of metal atoms into $\pi$ conjugated systems allows many variables to be adjusted, such as the nature of ligands and metal ions as well as the symmetry of the complexes. In this paper, new ruthenium(II) complexes of formula $\left[\mathrm{Ru}(\mathrm{bpy})_{2}(\mathrm{~L})\right]\left[\mathrm{PF}_{6}\right]$ and $\left[\mathrm{Ru}(\mathrm{L})_{3}\right]\left[\mathrm{PF}_{6}\right]_{2}$ are reported. We studied the influence of the nature of ligands, structural features and symmetry of these complexes on their two-photon absorption properties to provide useful physical and chemical insights for similar ruthenium complexes.
\end{abstract}

Keywords: Coordination complexes, ruthenium, $\pi$-conjugated systems linear optical properties , nonlinear optical properties, two-photon absorption.

\section{INTRODUCTION}

Two-photon absorption (2PA), a nonlinear optical phenomenon in which a molecule absorbs two photons of identical or different frequencies at the same time (Figure 1, left), has received tremendous attention owing to its advantages when compared to alternative techniques, which include the ability for spatiotemporal control of excitation and intrinsic three-dimensional resolution together with increased penetration depth in tissues or materials.[1] Such benefits meet the prerequisites for promising applications from materials science to medicine such as optical limiting, microfabrication, 3D optical data processing and storage, bio-imaging, and photodynamic therapy. Experimental studies provided different classes of molecules with high two-photon absorption cross sections $(\sigma)$ by: i) including $\mathrm{D}-\pi-\mathrm{A}$ chromophores $(\mathrm{D}=$ donor and $\mathrm{A}=$ acceptor) and extending the molecular conjugated system within these $\mathrm{D}-\pi-\mathrm{A}$ chromophores ii) increasing the strength of donoracceptor interactions while preserving planarity and rigidity of the $\pi$-conjugated core for charge transfer in $\pi$ conjugated organic compounds iii) incorporating multi-dipole or quadrupole chromophores into a molecular structure.[2-4] Theoretical calculations also anticipated the superiority of octupolar molecules versus dipolar molecules as far as the transparency/nonlinearity is concerned.[5, 6]

In this context, coordination complexes have been the focus of intense investigations for designing efficient Two-Photon absorbers.[7, 8] The coordination of conjugated ligands to transition metal centers results in a drastic enlargement of the NLO responses, especially second harmonic generation (SHG). In most cases, the observed NLO properties are associated with charge-transfer transitions between the metal and the ligand, such as intraligand charge-transfer (ILCT), metal-ligand charge-transfer (MLCT), ligand-to-metal charge transition (LMCT), within the complexes (Figure 1, right).[9] Charge-transfers also favor large two-photon absorption cross sections $(\sigma)$ values, as the increase of $\sigma$ in multipolar chromophores is related to the proliferation of excited states opening additional electronic channels for 2PA.[10-12]

Octahedral $\mathrm{Ru}(\mathrm{II})$ polypyridyl complexes attracted major attention because of their photophysical, photochemical and $2^{\text {nd }}$ order NLO properties. Much less studies were devoted to understand and interpretate the 2PA properties of such complexes. Pioneering papers showed that metal-to-ligand charge transfer (MLCT) excited states could be obtained through multi-photon processes.[13, 14] In 2002, Yamagishi evaluated the 2PA cross-section of a tris-phenanthroline-ruthenium(II) complex using a fluorescence-based technique.[15] In more recent years, polypyridyl ruthenium complexes with TPE (two-photon excited emission) property have attracted great interest due to their attractive photophysical properties, especially for bioimaging and therapeutic agent applications.[16] 


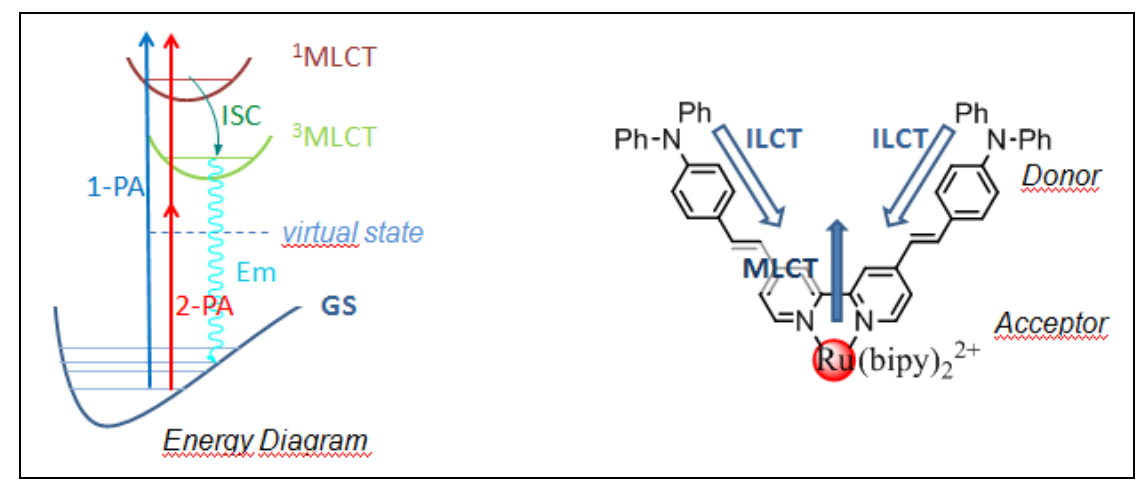

Figure 1. Left: Simplified Jablonski diagram for one-photon and two-photon excitations in Ru(II) polypyridyl complexes. Excitations occur between the ground state and the vibrational levels of the first electronic excited state. One-photon excitation occurs through the absorption of a single photon. Two-photon excitation occurs through the absorption of two lower-energy photons via short-lived intermediate states. After either excitation process, the fluorophore relaxes to the lowest energy level of the first excited electronic states ${ }^{1} M L C T$ via vibrational processes, followed by intersystem crossing to the to the lowest triplet state of the complexes from where emission occurs. The subsequent emission processes for both relaxation modes are thus the same. Right: Schematic diagram of the main charge transfer processes in Ru(II) polypyridyl complexes.

\section{RESULTS AND DISCUSSION}

We have developed two series of 4,4'-disubstituted-[2,2`]-bipyridine ligands (La,b) (Figure 2) for investigating the dependence of the $2 \mathrm{PA}$ cross-section on structural features of the corresponding homoleptic $\left[\mathrm{Ru}(\mathbf{L})_{3}\right]^{2+}$ and heteroleptic $\left[\mathrm{Ru}(\mathbf{L})(\text { bipy })_{2}\right]^{2+}$ complexes. In these systems, the metal center would not only acts as a Lewis acid to induce a strong intraligand charge-transfer (ILCT) transition but also as a powerful template to gather ligands in a predetermined octupolar arrangement in the case of homoleptic $\left[\mathrm{Ru}(\mathbf{L})_{3}\right]^{2+}$ complexes. Both the ligands and Ruthenium complexes feature excellent emission properties. Therefore, the two-photon absorption cross-sections were measured using the TPEF (two-photon excited fluorescence) method (Figures 2 and 3).

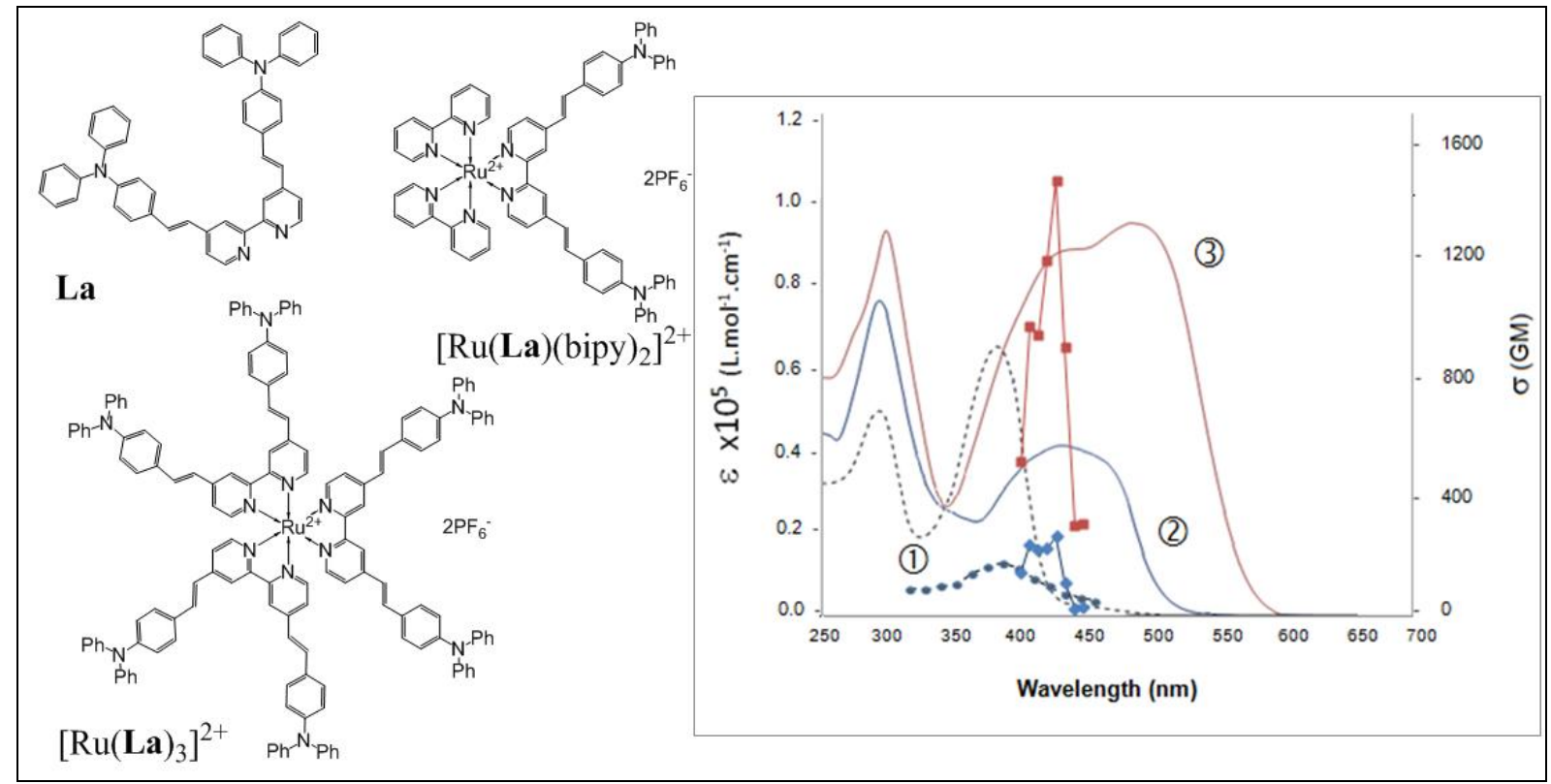

Figure 2. Left : Chemical structures of La, $\left[R u(\text { La })(\text { bipy })_{2}\right]^{2+},\left[R u(L \boldsymbol{L a})_{3}\right]^{2+}$. Right: 1PA and 2 PA spectra for La (dotted curves; (1)), $\left[\mathrm{Ru}(\boldsymbol{L a})(\text { bipy })_{2}\right]^{2+}$ (blue curves; (2)), $\left[\mathrm{Ru}(\boldsymbol{L a})_{3}\right]^{2+}$ (red curves; (3)), in $\mathrm{CH}_{2} \mathrm{Cl}_{2}\left(10^{-6} \mathrm{M}\right)$.

The main 1 Photon- and 2 Photon-absorption and emission characteristics for each compound are compiled in Table 1. The ligands La,b exhibit similar 2PA bands with maxima absorption wavelengths twice that of their linear absorption ones. This effect clearly indicates that the low-energy ILCT transition is two-photon active which is consistent with the non-centrosymmetric feature of these chromophores. The maximum 2PA cross section $208 \mathrm{GM}$ at $780 \mathrm{~nm}\left(1 \mathrm{GM}\right.$ is $10^{-50} \mathrm{~cm}^{4} \mathrm{~s}_{\text {photon }}^{-1}$, error is $\left.\sim 15 \%\right)$ is slightly higher for the fluorenyl containing ligand $\mathbf{L b}$ compared to $\mathbf{L a}, \sim 187 \mathrm{GM}$ at $780 \mathrm{~nm}$. This enhancement can be related to the extension of the conjugated $\pi$-system in $\mathbf{L b}$ to be compared to $\mathbf{L a}$. 


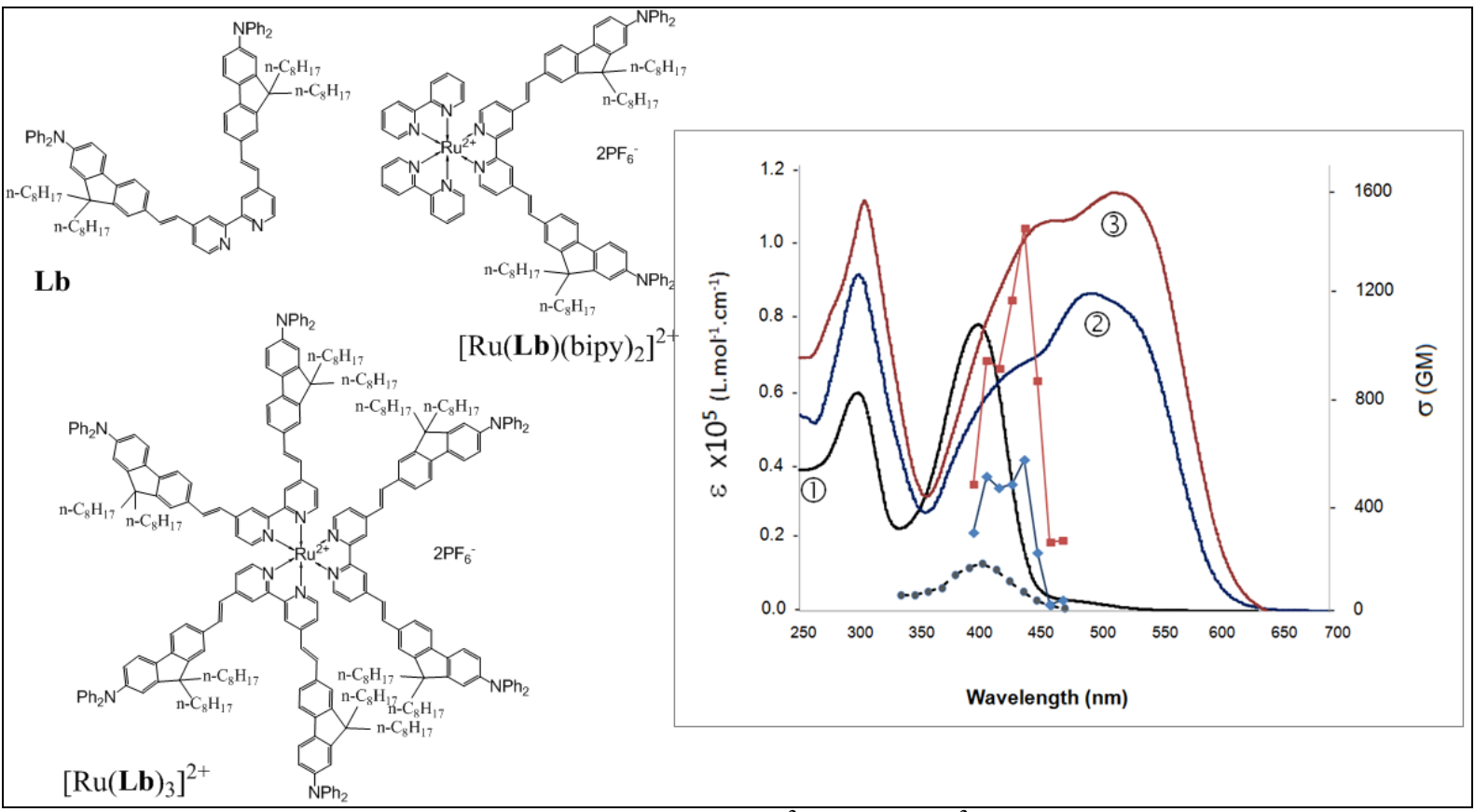

Figure 3. Left: Chemical structures of $\boldsymbol{L b},\left[R u(\boldsymbol{L b})(\text { bipy })_{2}\right]^{2+},\left[R u(\boldsymbol{L} \boldsymbol{b})_{3}\right]^{2+}$. Right: 1PA and $2 P A$ spectra for $\boldsymbol{L b}$ (black curves; (1)), $\left[\mathrm{Ru}(\boldsymbol{L b})(\text { bipy) })_{2}\right]^{2+}$ (blue curves; (2)), $\left[\mathrm{Ru}(\boldsymbol{L b})_{3}\right]^{2+}$ (red curves; (3)), in $\mathrm{CH}_{2} \mathrm{Cl}_{2}\left(10^{-6} \mathrm{M}\right)$.

The coordination of the ligands to the metal center leads to substantial changes of the 2PA spectra. As expected, the coordination to the $\mathrm{Ru}(\text { bipy })_{2}{ }^{2+}$ fragment induces a red shift of the 2PA band in both cases $(\sim 0.15$ $\mathrm{eV}$ ) (Fig. 2). The maximum 2PA cross-section is enhanced by a factor $\sim 2.5$ for both $\mathrm{Ru}\left(\right.$ bipy) ${ }_{2} \mathrm{~L}^{2+}$ complexes, as compared to the corresponding ligands. This effect is attributed to the Lewis acidity of the $\mathrm{Ru}$ (bipy) ${ }_{2}{ }^{2+}$ fragment which promotes a stronger electron-withdrawing ability of bipyridyl and strengthens the charge transfer character of the ILCT transition. The maximum $2 \mathrm{PA}$ cross section (596 GM at $860 \mathrm{~nm}$, error is $\sim 15 \%$ ) is higher for the fluorenyl compound RuLb compared to its analog RuLa (311 GM at $850 \mathrm{~nm}$ ). This may be attributed in the larger $\pi$-delocalization in the fluorenyl bridged ligands. Surprinsigly, the maximum 2PA cross sections for the two homoleptic $\mathrm{RuL}_{3}{ }^{2+}$ complexes are in the reverse order $\left(\left[\operatorname{Ru}(\mathbf{L b})_{3}\right]^{2+}: 1315 \mathrm{GM}\right.$ and $\left[\mathrm{Ru}(\mathbf{L a})_{3}\right]^{2+}: 1500 \mathrm{GM}$ at $850-860 \mathrm{~nm}$ ).

Table 1. Comparison of the 1PA wavelength $\lambda_{\text {max }}$ absorption coefficient, emission wavelength $\lambda_{\text {em }}$ quantum yields $\varphi_{\text {em }}$ and $2 P A$ cross section $\sigma$ at $\lambda_{\max }$ for each compound.

\begin{tabular}{|c|c|c|c|c|c|}
\hline & $\lambda_{\max }(\mathrm{nm})$ & $\varepsilon\left(10^{3} \mathrm{M}^{-1} \mathrm{~cm}^{-1}\right)$ & $\lambda_{\mathrm{em}}(\mathrm{nm})$ & $\varphi_{\mathrm{em}}$ & $\sigma(\mathrm{GM})$ \\
\hline $\mathbf{L a}$ & 297,397 & 58,77 & 500 & 0.76 & 187 \\
\hline$\left[\mathrm{Ru}(\mathbf{L a})(\text { bipy })_{2}\right]^{2+}$ & $299,440,479$ & $92,65,85$ & 705 & 0.018 & 311 \\
\hline$\left[\mathrm{Ru}(\mathbf{L a})_{3}\right]^{2+}$ & $304,455,510$ & $110,105,112$ & 710 & 0.04 & 1500 \\
\hline $\mathbf{L b}$ & 276,402 & 208,69 & 546 & 0.86 & 220 \\
\hline$\left[\mathrm{Ru}(\mathbf{L b})(\text { bipy })_{2}\right]^{2+}$ & $292,417,497$ & $98,54,62$ & 711 & 0.018 & 596 \\
\hline$\left[\mathrm{Ru}(\mathbf{L b})_{3}\right]^{2+}$ & $309,421,506$ & $179,153,136$ & 720 & 0.04 & 1315 \\
\hline
\end{tabular}

Very small differences are observed between the 2PA spectral shape and position of the maximum 2PA peak for the four complexes. Meanwhile, the 2PA spectra of the complexes differ from the corresponding 1PA ones, through a blue-shift of the relative lowest energy peak position $(\sim 0.4 \mathrm{eV})$ and a reduction of the peak width. This blue shift can be attributed to parity selection rules, which favor excitation to higher energy levels than the respective one-photon induced transitions. [10,11] Actually, the four complexes exhibit 2PA bands with maxima absorption wavelengths almost twice that of the linear absorption ILCT bands. Unfortunately, the spectral accessible window $(780-920 \mathrm{~nm}$ ) for two-photon excitation is a limit to what we can conclude in absolute about the two-photon spectra and the comparison with the 1PA spectra, and more specifically about absorption wavelengths situated twice that of the linear absorption MLCT bands. Meanwhile, the similarity in the spectral shape of the ILCT bands and the 2PA spectra suggests that the first excited state is both one and two-photon allowed, which corresponds to the classical behavior of dipolar or multi-dipolar structures, with a reduced 
symmetry. The distortion from the expected octahedral structure in the homoleptic complexes could result from the relative flexibility of the bipyridine ligands.[17]

\section{CONCLUSIONS}

In this paper, the $2 \mathrm{PA}$ cross-section values of two series of $\mathrm{Ru}(\text { bipy })_{2} \mathrm{~L}^{2+}$ and $\mathrm{RuL}_{3}{ }^{2+}$ coordination compounds have been reported and compared to the parent ligands. Both homoleptic and heteroleptic compounds feature excellent TPE fluorescence properties with high two-photon cross-sections. The variation of 2PA cross section in each series seems to correspond to both an enhancement due to the coordination to the $\mathrm{Ru}(\mathrm{bipy})_{2}{ }^{2+}$ fragment which strengthens the charge transfer character of the ILCT transition and to an additive relationship with the number of extended bipyridine ligands. Complementary studies with these complexes and other ligands as well as the corresponding complexes are in progress in our group to confirm this behavior.

\section{REFERENCES}

[1] H.M. Kim, B.R. Cho, Small-Molecule Two-Photon Probes for Bioimaging Applications, Chem. Rev. 115 (2015) 5014-5055.

[2] K. Belfield, S. Yao, M. Bondar, Two-photon Absorbing Photonic Materials: From Fundamentals to Applications, in: S. Marder, K.-S. Lee (Eds.), Photoresponsive Polymers I, Springer Berlin / Heidelberg2008, pp. 97-156.

[3] G.S. He, L.-S. Tan, Q. Zheng, P.N. Prasad, Multiphoton Absorbing Materials: Molecular Designs, Characterizations, and Applications, Chem. Rev. 108 (2008) 1245-1330.

[4] D. Beljonne, W. Wenseleers, E. Zojer, Z. Shuai, H. Vogel, S.J. Pond, J.W. Perry, S.R. Marder, J.-L. Brédas, Role of dimensionality on the two-photon absorption response of conjugated molecules: the case of octupolar compounds, Adv. Funct. Mater. 12 (2002) 631-641.

[5] C. Katan, S. Tretiak, M.H.V. Werts, A.J. Bain, R.J. Marsh, N. Leonczek, N. Nicolaou, E. Badaeva, O. Mongin, M. Blanchard-Desce, Two-Photon Transitions in Quadrupolar and Branched Chromophores:

Experiment and Theory, J. Phys. Chem. B 111 (2007) 9468-9483.

[6] F. Terenziani, C. Katan, E. Badaeva, S. Tretiak, M. Blanchard-Desce, Enhanced Two-Photon Absorption of Organic Chromophores: Theoretical and Experimental Assessments, Adv. Mater. 20 (2008) 4641-4678.

[7] M. Pawlicki, H.A. Collins, R.G. Denning, H.L. Anderson, Two-Photon Absorption and the Design of TwoPhoton Dyes, Angew. Chem. Int. Ed. 48 (2009) 3244-3266.

[8] X.-B. Zhang, J.-K. Feng, A.-M. Ren, Theoretical Study of One-and Two-Photon Absorption Properties of Octupolar D 2 d and D 3 Bipyridyl Metal Complexes, J. Phys. Chem. A 111 (2007) 1328-1338.

[9] S. Di Bella, C. Dragonetti, M. Pizzotti, D. Roberto, F. Tessore, R. Ugo, Coordination and organometallic complexes as second-order nonlinear optical molecular materials, Molecular Organometallic Materials for Optics, Springer2010, pp. 1-55.

[10] C. Girardot, B. Cao, J.C. Mulatier, P.L. Baldeck, J. Chauvin, D. Riehl, J.A. Delaire, C. Andraud, G. Lemercier, Ruthenium (II) Complexes for Two-Photon Absorption-Based Optical Power Limiting, Chem. Phys. Chem. 9 (2008) 1531-1535.

[11] C. Girardot, G. Lemercier, J.C. Mulatier, J. Chauvin, P.L. Baldeck, C. Andraud, Novel ruthenium(II) and zinc(II) complexes for two-photon absorption related applications, Dalton Trans (2007) 3421-3426.

[12] F. Khammar, A.P. Kerasidou, K. Iliopoulos, P. Savel, H. Akdas-Kilig, Y. Hamaizi, J.L. Fillaut, B. Sahraoui, Effect of metal complexation on the nonlinear optical response of a conjugated ligand, Journal of the Optical Society of America B-Optical Physics 31 (2014) 1555-1560.

[13] F.N. Castellano, H. Malak, I. Gryczynski, J.R. Lakowicz, Creation of Metal-to-Ligand Charge Transfer Excited States with Two-Photon Excitation, Inorg. Chem. 36 (1997) 5548-5551.

[14] D.W. Thompson, J.F. Wishart, B.S. Brunschwig, N. Sutin, Efficient Generation of the Ligand Field Excited State of Tris-(2,2'-bipyridine)-ruthenium(II) through Sequential Two-Photon Capture by [Ru(bpy)3]2+ or Electron Capture by [Ru(bpy)3]3+, J. Phys. Chem. A 105 (2001) 8117-8122.

[15] J. Kawamata, Y. Ogata, A. Yamagishi, Two-Photon Fluorescence Property of Tris(4,7-Diphenyl-1,10phenanthroline)ruthenium(II)perchlorate, Mol. Cryst. Liq. Cryst. 379 (2002) 389-394.

[16] Y. Chen, R. Guan, C. Zhang, J. Huang, L. Ji, H. Chao, Two-photon luminescent metal complexes for bioimaging and cancer phototherapy, Coord. Chem. Rev. 310 (2016) 16-40.

[17] C.W. Stark, M. Rammo, J. Pahapill, A. Mikhaylov, A. Rebane, Probing metal-to-ligand charge transfer transitions in ruthenium complexes by quantitative two-photon absorption spectroscopy, Organic Photonic Materials and Devices XX, International Society for Optics and Photonics, 2018, pp. 105291D. 